\title{
Analysis of Various Machining Parameters of Electrical Discharge Machining (EDM) on Hard Steels using Copper and Aluminium Electrodes
}

\author{
Ashwani Kharola \\ Institute of Technology Management (ITM), Defence R\&D Organisation (DRDO), Mussoorie-248169, \\ Uttarakhand, India
}

\begin{abstract}
EDM is a non-contact machining process widely used for shaping electro-conductive materials regardless of their hardness. In EDM material removal takes place by a series of recurring electrical sparks between the tool electrode and workpiece. In this study the effect of variation of discharge current on various machining parameters including Metal removal rate (MRR), Tool removal rate (TRR) and Surface roughness has been considered. A total of 32 experiments were conducted on four different workpieces i.e. Die Steel-D3, En-8, En19 and Stainless steel (SS-AISI-440C) with the help of Copper and Aluminium electrodes. In this study DieSinking EDM has been employed and the results are shown with the help of graphs.
\end{abstract}

Index Terms: EDM, Die-Sinking, MRR, TRR and Surface roughness.

(C) 2015 Published by MECS Publisher. Selection and/or peer review under responsibility of the Research Association of Modern Education and Computer Science.

\section{Introduction}

EDM is one of the most widely used non-conventional machining processes[1] which uses electrical spark to erode unwanted material and creates desired shape[2]. It involves thermoelectric transition between tool and work electrode to form replica of tool on workpiece [3]. It is widely used to produce dies, tools, fixtures, gauges, punches and moulds, finishing parts for aerospace and automotive industry etc $[4,5]$. Modern EDM is capable of machining geometrically complex and hard material such as heat treated tool steels, composites, super alloys etc $[6,7]$. A servomechanism maintains a small gap between the electrodes thus preventing them from coming into contact with each other [9] as a result a very small force is exerted on both workpiece and tool electrode[8].

There has been lots of research done on various advent of EDM [10,11]. Yoshio mizugaki [13] proposed a new approach of contouring EDM by means of on-machine measuring and dressing of a ball-nosed cylindrical

* Corresponding author. Tel.:

E-mail address: ashwanidaa@gmail.com 
graphite electrode. Y.F.Tzeng and N.H.Chiu [14] proposed a two-phase parameter design for the optimization of the EDM process using a Taguchi dynamic experiment. P.M George, B.K.Raghunath, L.M.Manocha and A.M.Warrier [15] performed machining of carbon-carbon composites on EDM. S.R.Nithin Aravind, S.Sowmyi and K.P.Yuvara [16] have shown optimization of MRR and surface roughness on wire EDM using Taguchi method. Samad Dadvandipour [12] presented an experimental study of EDM on P-20 type tool steel. K.K Dadsena, S.Sivasankar, and C.R.Jeyapaul [17] analysed machinability behaviour of ZrB2-SiC using different tool material. Chen Jian, Sun Zhong-Ming and LU Guo-Dong [18] proposed a new methodology to solve electrode wear compensation in die-sinking EDM using wear simulation method. In this research, study is done on the Die-Sinking EDM [19], in which two electrodes i.e. tool and workpiece are submerged in a dielectric and are connected to a source of power supply.

\section{Working Principle of EDM}

In EDM, a potential difference is applied between the tool and the workpiece. Both the tool and the work material are conductors of electricity. The electrodes are immersed in a dielectric medium. Generally kerosene or demonized water is used as the dielectric [26]. A gap is maintained between the tool and the workpiece. Depending upon the applied potential difference and electrode gap, an electric field is established between the electrodes [20]. As the electric field is established, the free electrons on the tool are subjected to electrostatic forces. If the work function or the bonding energy of the electrons is less, electrons are emitted from the tool (assuming it to be connected to the negative terminal). The electrons are then accelerated towards the job through the dielectric medium resulting in collisions between the electrons and the dielectric molecules. Such collisions may result in ionization of the dielectric molecule. Thus, as the electrons get accelerated, more positive ions and electrons would get generated due to collisions.

This cyclic process increases the concentration of electrons and ions at the spark gap. The concentration increases so much that the matter existing in that channel becomes plasma [21]. The electrical resistance of such plasma channel is very less. Thus all of sudden, a large number of electrons flow from tool to workpiece and the ions from workpiece to tool. Such movement of electrons and ions can be visually seen as a spark. The high speed electrons then impinge on work and ions on the tool. The kinetic energy of the electrons and ions on impact with the surface of workpiece and tool respectively would be converted into thermal energy or heat flux. Such intense localised heat flux leads to extreme instantaneous confined rise in temperature which would be in excess of $10,000{ }^{\circ} \mathrm{C}$ thus leading to material removal [22]. Material removal occurs due to instant vaporisation of the material as well as due to melting. As the potential difference is withdrawn the plasma channel is no longer sustained. As the plasma channel collapse, it generates pressure or shock waves, which evacuates the molten material. The working principle of EDM is shown in figure 1.0. [23].

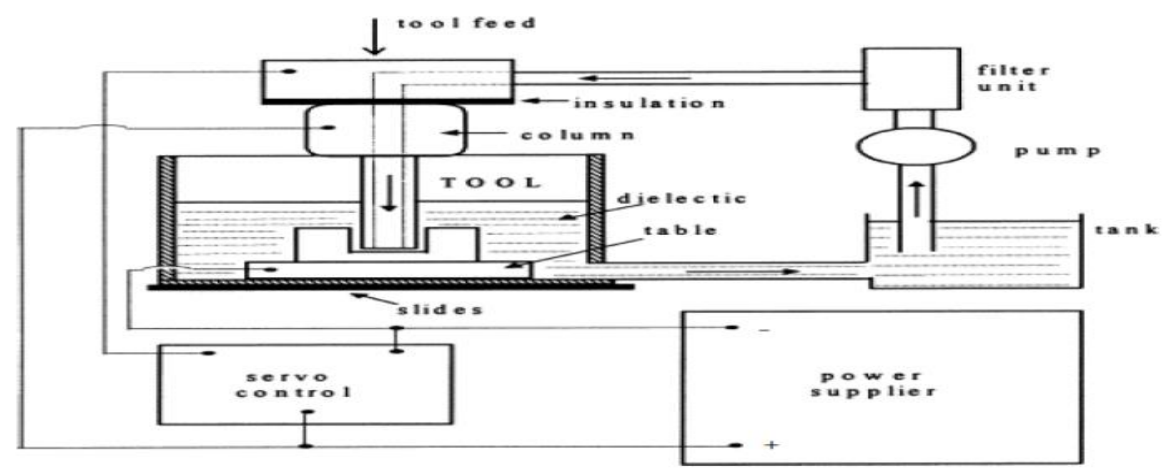

Fig. 1. Working principle of EDM 


\section{EDM Experimental procedure}

In this study PS LEADER ZNC (Die sinking type) EDM was used to conduct experiments. A view of PS LEADER ZNC EDM is shown in figure 1.1. Hard materials needed for the study were provided from Nova Sara Industry, Dehradun. This study reports the effect of machining parameter (Pulse discharge current) on Material removal rate (MRR), Tool removal rate (TRR) and Surface roughness for machining Die Steel-D3, En-8, En-19 and Stainless steel (SS-AISI-440C) [25]. The polarity used for the experiments is reversed polarity i.e. tool electrode is given positive polarity and work piece is given negative polarity [27]. In this study Copper and Aluminium electrodes [24] are used, two electrodes are formed from each material having rectangular shape of size $16 \mathrm{~mm} * 24 \mathrm{~mm}$. Upper part of the electrode is made of mild steel which is brazed to the copper and aluminium pieces to form the tool electrode.

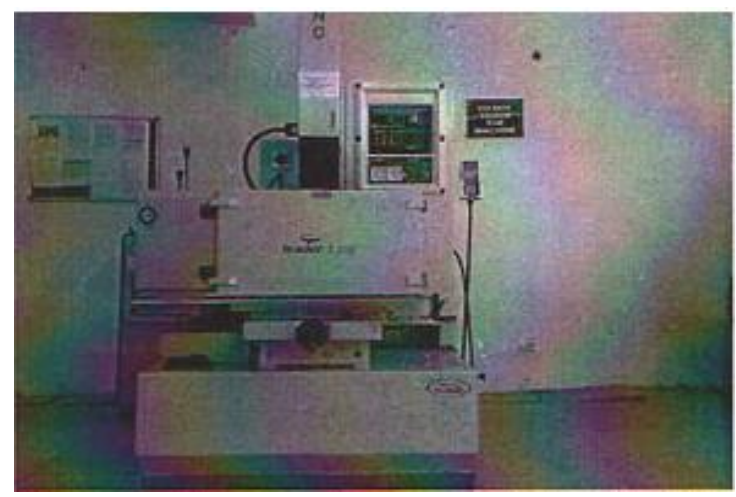

Fig. 1.1 PS LEADER ZNC EDM

The Metallurgical compositions of Workpieces used in the study are shown in Table 1.0

Table 1.0 Metallurgical composition of the workpieces

\begin{tabular}{|ccccc|}
\hline Material & En-8 & Die Steel D3 & En-19 & SS-AISI-440C \\
\hline $\mathbf{C}$ & $0.35-0.45$ & $2-2.35$ & $0.35-0.45$ & $0.95-1.20$ \\
\hline $\mathbf{M n}$ & $0.05-0.35$ & 0.6 & $0.5-0.8$ & 1.0 \\
\hline $\mathbf{S i}$ & ----- & 0.6 & $0.1-0.35$ & 1.0 \\
\hline $\mathbf{C r}$ & ----- & $11-13.5$ & $0.9-1.50$ & $16-18$ \\
\hline $\mathbf{N i}$ & 0.06 & 0.3 & ----- & ----- \\
\hline $\mathbf{S}$ & 0.06 & 0.03 & 0.05 & 0.03 \\
\hline $\mathbf{P}$ & ----- & 0.03 & 0.05 & 0.04 \\
\hline $\mathbf{M o}$ & ----- & ----- & $0.2-0.4$ & 0.75 \\
\hline $\mathbf{V}$ & ----- & ----- & $0.2-0.4$ & 0.75 \\
\hline $\mathbf{W}$ & ----- & 1 & ----- & ----- \\
\hline
\end{tabular}


The quantity of electrodes and workpieces used for experiments are shown in Table 1.1 and Table 1.2 respectively. A view of both the Copper and Aluminium electrodes are shown in figure 1.2 and figure 1.3 respectively.

Table 1.1 Quantity of tool electrodes

\begin{tabular}{|lll|}
\hline S.No & Electrode & Quantity \\
\hline $\mathbf{1}$ & Copper & 2 Nos. \\
\hline $\mathbf{2}$ & Aluminium & 2 Nos. \\
\hline
\end{tabular}

Table 1.2 Quantities of Workpieces

\begin{tabular}{|lll|}
\hline S.No & Workpiece & Quantity \\
\hline $\mathbf{1}$ & Die Steel-D3 & 3 Nos. \\
\hline $\mathbf{2}$ & En-8 & 2 Nos. \\
\hline $\mathbf{3}$ & En-19 & 5 Nos. \\
\hline $\mathbf{4}$ & SS-AISI-440C & 1 Nos \\
\hline
\end{tabular}

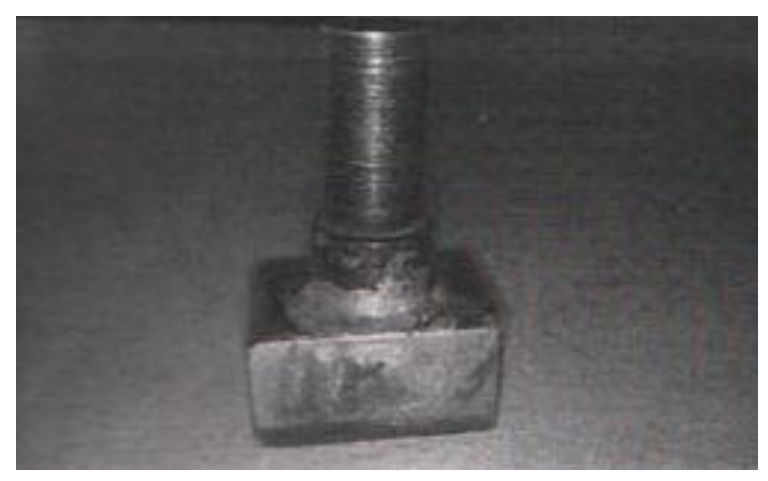

Fig. 1.2 Finished Copper electrode

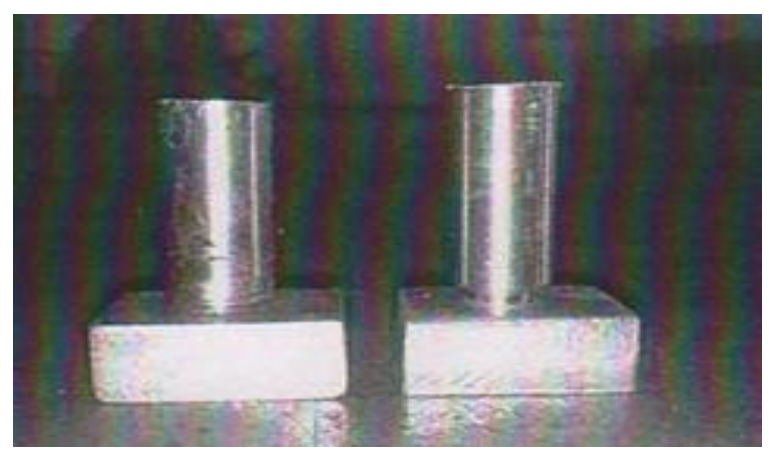

Fig. 1.3 Finished Aluminium electrodes

A total of 32 experiments were conducted, initial weight in grams (Wi) of workpiece and electrode were measured with the help of single pan electrical balancer as shown in figure 1.4. 


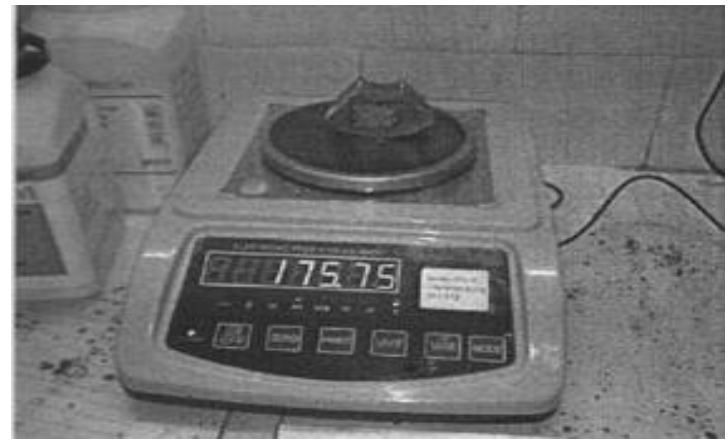

Fig. 1.4 Weighing of workpiece on electrical balance

Workpieces were then mounted on magnetic clamp and tool electrode was fixed to end of the quill with a clamping device in EDM. Depth of cut for machining was set to $3 \mathrm{~mm}$ and $2 \mathrm{~mm}$, for $\mathrm{Cu}$ and $\mathrm{Al}$ electrode respectively. A thin gap about $0.025 \mathrm{~mm}$ is maintained between the tool and workpiece by a servo system. The pulse discharge current was applied in various steps. The other parameters such as gap voltage, pulse on time, percent duty cycle, quill speed, work time etc were kept constant. After machining, final weight in grams (Wf) of tool and workpieces were again measured. A surface roughness tester (LC $0.01 \mu \mathrm{m})$ was used for measuring Ra values in $\mu \mathrm{m}$. A view of different workpieces after machining are shown from figure 1.5 to figure 1.8.

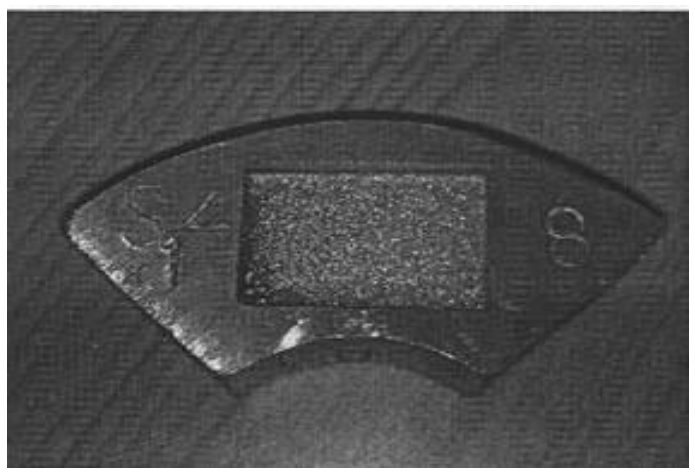

Fig 1.5 En-19 Workpiece after machining

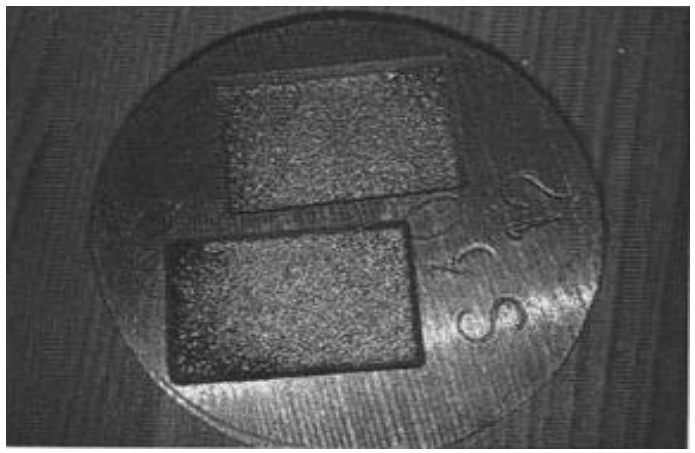

Fig 1.6 En-8 Workpiece after machining 


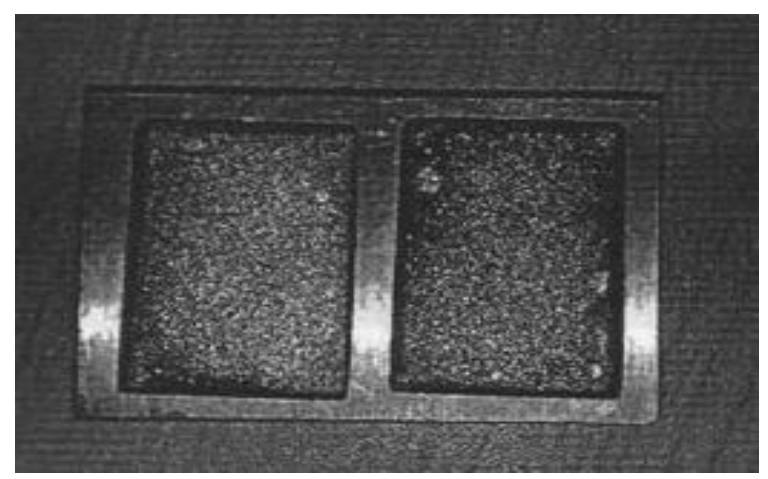

Fig 1.7 Die Steel workpiece after machining

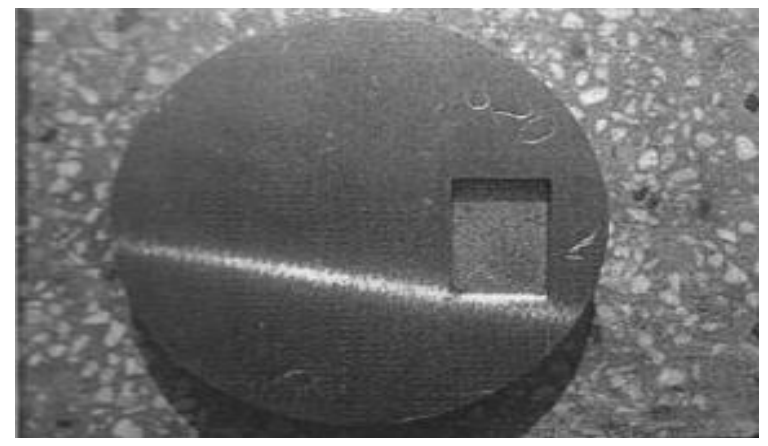

Fig 1.8 Stainless Steel workpiece after machining

\section{Tables of Experiments}

\subsection{Values of Ra for different workpieces using $C u$ electrodes}

Table 1.3 Values of Ra for Die Steel D3 using Cu electrode

\begin{tabular}{|c|c|c|c|c|c|}
\hline Exp No. & & 1 & 2 & 3 & 4 \\
\hline \multirow{3}{*}{$\begin{array}{l}\text { Electrode } \\
\text {-Copper }\end{array}$} & Wi & 61.65 & 59.38 & 59.19 & 58.9 \\
\hline & Wf & 61.64 & 59.35 & 59.14 & 58.85 \\
\hline & (Wf-Wi) & 0.01 & 0.03 & 0.05 & 0.06 \\
\hline \multirow{3}{*}{$\begin{array}{c}\text { Workpiece } \\
\text {-Die Steel D3 }\end{array}$} & Wi & 75.99 & 96.08 & 86.32 & 67.03 \\
\hline & Wf & 67.03 & 86.32 & 75.1 & 58.85 \\
\hline & (Wf-Wi) & 8.96 & 9.76 & 11.22 & 8.18 \\
\hline $\begin{array}{l}\text { Depth of cut } \\
(\mathrm{mm})\end{array}$ & & 3 & 3 & 3 & 3 \\
\hline Time (min) & & 110 & 81.5 & 46.3 & 33.5 \\
\hline $\begin{array}{l}\text { Gap Current } \\
\text { Ip (Amp) }\end{array}$ & & 6 & 9 & 12 & 15 \\
\hline $\begin{array}{c}\text { Gap Voltage } \\
\text { Vg (Volts) }\end{array}$ & & 50 & 50 & 50 & 50 \\
\hline $\mathbf{R a}$ & & 3.2 & 3.73 & 3.89 & 4.64 \\
\hline
\end{tabular}


Table 1.4 Value of Ra for SS-AISI-440C using Cu electrode

\begin{tabular}{|c|c|c|c|c|c|}
\hline Exp No. & & 1 & 2 & 3 & 4 \\
\hline \multirow{3}{*}{$\begin{array}{l}\text { Electrode } \\
\text {-Copper }\end{array}$} & Wi & 61.64 & 59.35 & 59.14 & 58.65 \\
\hline & Wf & 61.62 & 59.28 & 59.07 & 58.58 \\
\hline & (Wf-Wi) & 0.02 & 0.07 & 0.07 & 0.07 \\
\hline \multirow{3}{*}{$\begin{array}{c}\text { Workpiece } \\
\text {-SS-AISI-440C }\end{array}$} & $\mathrm{Wi}$ & 383.51 & 374.84 & 365.36 & 355.86 \\
\hline & Wf & 374.84 & 365.36 & 355.86 & 346.17 \\
\hline & (Wf-Wi) & 8.67 & 9.48 & 9.5 & 9.69 \\
\hline $\begin{array}{c}\text { Depth of cut } \\
(\mathrm{mm})\end{array}$ & & 3 & 3 & 3 & 3 \\
\hline Time (min) & & 124 & 67 & 49 & 34 \\
\hline $\begin{array}{c}\text { Gap Current } \\
\text { Ip (Amp) }\end{array}$ & & 6 & 9 & 12 & 15 \\
\hline $\begin{array}{c}\text { Gap Voltage } \\
\text { Vg (Volts) }\end{array}$ & & 50 & 50 & 50 & 50 \\
\hline $\mathbf{R a}$ & & 2.85 & 3.80 & 3.85 & 4.01 \\
\hline
\end{tabular}

Table 1.5 Values of Ra for En-8 using Cu electrode

\begin{tabular}{|c|c|c|c|c|c|}
\hline Exp No. & & 1 & 2 & 3 & 4 \\
\hline \multirow{3}{*}{$\begin{array}{l}\text { Electrode } \\
\text {-Copper }\end{array}$} & $\mathrm{Wi}$ & 61.62 & 59.28 & 59.00 & 58.75 \\
\hline & Wf & 61.60 & 59.25 & 58.91 & 58.65 \\
\hline & (Wf-Wi) & 0.02 & 0.03 & 0.09 & 0.1 \\
\hline \multirow{3}{*}{$\begin{array}{l}\text { Workpiece } \\
\text {-En -8 }\end{array}$} & $\mathrm{Wi}$ & 196.63 & 187.52 & 177.69 & 167.95 \\
\hline & Wf & 187.52 & 177.69 & 167.95 & 158.24 \\
\hline & (Wf-Wi) & 9.11 & 9.83 & 9.74 & 9.71 \\
\hline $\begin{array}{l}\text { Depth of cut } \\
\text { (mm) }\end{array}$ & & 3 & 3 & 3 & 3 \\
\hline Time (min) & & 154 & 64 & 40.6 & 37 \\
\hline $\begin{array}{l}\text { Gap Current } \\
\text { Ip (Amp) }\end{array}$ & & 6 & 9 & 12 & 15 \\
\hline $\begin{array}{c}\text { Gap Voltage } \\
\text { Vg (Volts) }\end{array}$ & & 50 & 50 & 50 & 50 \\
\hline $\mathbf{R a}$ & & 4.03 & 4.32 & 4.69 & 4.95 \\
\hline
\end{tabular}

Table 1.6 Values of Ra for En-19 using Cu electrode

\begin{tabular}{|c|c|c|c|c|c|}
\hline Exp No. & & 1 & 2 & 3 & 4 \\
\hline \multirow{3}{*}{$\begin{array}{l}\text { Electrode } \\
\text {-Copper }\end{array}$} & Wi & 61.60 & 59.25 & 59.07 & 58.85 \\
\hline & Wf & 61.55 & 59.19 & 59.00 & 58.75 \\
\hline & (Wf-Wi) & 0.05 & 0.06 & 0.07 & 0.1 \\
\hline \multirow{3}{*}{$\begin{array}{l}\text { Workpiece } \\
\text { - En-19 }\end{array}$} & $\mathrm{Wi}$ & 161.66 & 196.05 & 188.69 & 185.66 \\
\hline & Wf & 152.65 & 185.94 & 178.83 & 175.75 \\
\hline & (Wf-Wi) & 9.01 & 10.11 & 9.86 & 9.91 \\
\hline $\begin{array}{c}\text { Depth of cut } \\
(\mathrm{mm})\end{array}$ & & 3 & 3 & 3 & 3 \\
\hline Time (min) & & 110 & 68 & 42.6 & 35 \\
\hline $\begin{array}{l}\text { Gap Current } \\
\text { Ip (Amp) }\end{array}$ & & 6 & 9 & 12 & 15 \\
\hline $\begin{array}{c}\text { Gap Voltage } \\
\text { Vg (Volts) }\end{array}$ & & 50 & 50 & 50 & 50 \\
\hline $\mathbf{R a}$ & & 3.10 & 3.32 & 3.55 & 3.90 \\
\hline
\end{tabular}




\subsection{Values of Ra for different workpieces using Al electrodes}

Table 1.7 Values of Ra for Die Steel D3 using Al electrode

\begin{tabular}{|c|c|c|c|c|c|}
\hline Exp No. & & 1 & 2 & 3 & 4 \\
\hline \multirow{3}{*}{$\begin{array}{c}\text { Electrode } \\
\text {-Aluminium }\end{array}$} & Wi & 16.90 & 14.72 & 17.30 & 16.77 \\
\hline & Wf & 16.55 & 14.21 & 16.77 & 16.24 \\
\hline & (Wf-Wi) & 0.35 & 0.51 & 0.53 & 0.53 \\
\hline \multirow{3}{*}{$\begin{array}{c}\text { Workpiece } \\
\text {-Die Steel D3 }\end{array}$} & $\mathrm{Wi}$ & 75.10 & 70.01 & 55.40 & 48.94 \\
\hline & Wf & 70.01 & 64.58 & 48.94 & 42.89 \\
\hline & (Wf-Wi) & 5.09 & 5.43 & 6.46 & 6.05 \\
\hline Depth of cut (mm) & & 2 & 2 & 2 & 2 \\
\hline Time (min) & & 61 & 31 & 31 & 22 \\
\hline $\begin{array}{l}\text { Gap Current } \\
\text { Ip (Amp) }\end{array}$ & & 6 & 9 & 12 & 15 \\
\hline $\begin{array}{c}\text { Gap Voltage } \\
\text { Vg (Volts) }\end{array}$ & & 50 & 50 & 50 & 50 \\
\hline $\mathbf{R a}$ & & 2.89 & 3.4 & 3.53 & 5.34 \\
\hline
\end{tabular}

Table 1.8 Values of Ra for SS-AISI-440C using Al electrode

\begin{tabular}{|c|c|c|c|c|c|}
\hline Exp No. & & 1 & 2 & 3 & 4 \\
\hline \multirow{3}{*}{$\begin{array}{l}\text { Electrode } \\
\text {-Aluminium }\end{array}$} & $\mathrm{Wi}$ & 16.55 & 15.76 & 13.12 & 15.58 \\
\hline & Wf & 16.20 & 15.23 & 12.60 & 15.16 \\
\hline & (Wf-Wi) & 0.35 & 0.53 & 0.52 & 0.42 \\
\hline \multirow{3}{*}{$\begin{array}{l}\text { Workpiece } \\
\text {-SS-AISI-440C }\end{array}$} & $\mathrm{Wi}$ & 346.17 & 339.84 & 329.30 & 323.04 \\
\hline & Wf & 339.84 & 334.21 & 323.04 & 317.48 \\
\hline & (Wf-Wi) & 6.33 & 5.63 & 6.26 & 5.56 \\
\hline Depth of cut (mm) & & 2 & 2 & 2 & 2 \\
\hline Time (min) & & 78 & 40.6 & 29 & 23 \\
\hline $\begin{array}{l}\text { Gap Current } \\
\text { Ip (Amp) }\end{array}$ & & 6 & 9 & 12 & 15 \\
\hline $\begin{array}{l}\text { Gap Voltage } \\
\text { Vg (Volts) }\end{array}$ & & 50 & 50 & 50 & 50 \\
\hline $\mathbf{R a}$ & & 2.66 & 3.92 & 3.90 & 4.09 \\
\hline
\end{tabular}

Table 1.9 Values of Ra for En-8 using Al electrode

\begin{tabular}{|c|c|c|c|c|c|}
\hline Exp No. & & 1 & 2 & 3 & 4 \\
\hline \multirow{3}{*}{$\begin{array}{c}\text { Electrode } \\
\text {-Aluminium }\end{array}$} & $\mathrm{Wi}$ & 15.23 & 11.26 & 11.99 & 16.24 \\
\hline & Wf & 14.72 & 10.59 & 11.26 & 15.58 \\
\hline & (Wf-Wi) & 0.51 & 0.67 & 0.65 & 2.66 \\
\hline \multirow{3}{*}{$\begin{array}{c}\text { Workpiece } \\
\text {-En-8 }\end{array}$} & $\mathrm{Wi}$ & 183.75 & 173.05 & 178.05 & 168.71 \\
\hline & Wf & 178.05 & 168.71 & 173.78 & 164.08 \\
\hline & (Wf-Wi) & 5.7 & 4.34 & 4.27 & 4.63 \\
\hline Depth of cut (mm) & & 2 & 2 & 2 & 2 \\
\hline Time $(\min )$ & & 65 & 42 & 22 & 25 \\
\hline $\begin{array}{l}\text { Gap Current } \\
\text { Ip (Amp) }\end{array}$ & & 6 & 9 & 12 & 15 \\
\hline $\begin{array}{c}\text { Gap Voltage } \\
\text { Vg (Volts) }\end{array}$ & & 50 & 50 & 50 & 50 \\
\hline $\mathbf{R a}$ & & 4.25 & 4.52 & 4.58 & 4.66 \\
\hline
\end{tabular}


Table 2.0 Values of Ra for En-19 using Al electrode

\begin{tabular}{|c|c|c|c|c|c|}
\hline Exp No. & & 1 & 2 & 3 & 4 \\
\hline \multirow{3}{*}{$\begin{array}{c}\text { Electrode } \\
\text {-Aluminium }\end{array}$} & Wi & 16.20 & 14.21 & 12.60 & 15.16 \\
\hline & $\mathrm{Wf}$ & 15.76 & 13.58 & 11.91 & 14.44 \\
\hline & (Wf-Wi) & 0.44 & 0.63 & 0.69 & 0.72 \\
\hline \multirow{3}{*}{$\begin{array}{c}\text { Workpiece } \\
\text {-En-19 }\end{array}$} & Wi & 185.94 & 178.83 & 175.75 & 159.7 \\
\hline & Wf & 180.46 & 174.15 & 171.06 & 154.30 \\
\hline & (Wf-Wi) & & & & \\
\hline $\begin{array}{c}\text { Depth of cut } \\
(\mathrm{mm})\end{array}$ & & 2 & 2 & 2 & 2 \\
\hline Time (min) & & 60 & 35 & 24 & 24 \\
\hline $\begin{array}{c}\text { Gap Current } \\
\text { Ip (Amp) }\end{array}$ & & 6 & 9 & 12 & 15 \\
\hline $\begin{array}{c}\text { Gap Voltage } \\
\text { Vg (Volts) }\end{array}$ & & 50 & 50 & 50 & 50 \\
\hline $\mathbf{R a}$ & & 2.85 & 3.59 & 3.96 & 4.15 \\
\hline
\end{tabular}

\subsection{Discharge current $v / s \operatorname{MRR}\left(\mathrm{mm}^{\wedge} 3 / \mathrm{min}\right)$}

Table 2.1 Values of MRR for various hard steels

\begin{tabular}{|c|c|c|c|c|}
\hline Current & 6A & 9A & 12A & 15A \\
\hline \multicolumn{5}{|c|}{ Die Steel } \\
\hline Cu Electrode & 10.44 & 15.35 & 31.07 & 31.30 \\
\hline Al Electrode & 10.69 & 22.45 & 26.71 & 35.25 \\
\hline \multicolumn{5}{|c|}{ SS-AISI-440C } \\
\hline Cu Electrode & 8.96 & 18.14 & 24.85 & 36.54 \\
\hline Al Electrode & 10.4 & 17.78 & 27.7 & 30.99 \\
\hline \multicolumn{5}{|c|}{ En-8 } \\
\hline Cu Electrode & 7.58 & 19.69 & 30.75 & 33.64 \\
\hline Al Electrode & 11.24 & 13.25 & 24.88 & 23.74 \\
\hline \multicolumn{5}{|c|}{ En-19 } \\
\hline Cu Electrode & 10.50 & 19.06 & 29.67 & 36.30 \\
\hline Al Electrode & 11.71 & 17.14 & 25.10 & 26.76 \\
\hline
\end{tabular}

\subsection{Discharge current v/s TRR (in \%)}

Table 2.2 Values of TRR for various hard steels

\begin{tabular}{|c|c|c|c|c|}
\hline Current & 6A & 9A & 12A & 15A \\
\hline \multicolumn{5}{|c|}{ Die Steel } \\
\hline Cu Electrode & 0.098 & 0.269 & 0.389 & 0.642 \\
\hline Al Electrode & 19.86 & 22.45 & 23.71 & 25.49 \\
\hline \multicolumn{5}{|c|}{ SS-AISI-440C } \\
\hline Cu Electrode & 0.201 & 0.645 & 0.648 & 0.632 \\
\hline Al Electrode & 16.1 & 27.2 & 23.99 & 21.82 \\
\hline \multicolumn{5}{|c|}{ En-8 } \\
\hline Cu Electrode & 0.193 & 0.267 & 0.809 & 0.904 \\
\hline Al Electrode & 25.01 & 44.59 & 43.98 & 41.18 \\
\hline \multicolumn{7}{|c|}{ En-19 } \\
\hline Cu Electrode & 0.486 & 0.520 & 0.623 & 0.884 \\
\hline Al Electrode & 23.2 & 38.9 & 42.6 & 41.5 \\
\hline
\end{tabular}


4.5 Graphs showing variation of various Machining parameters with discharge current using $\mathrm{Cu} \& \mathrm{Al}$ Electrodes

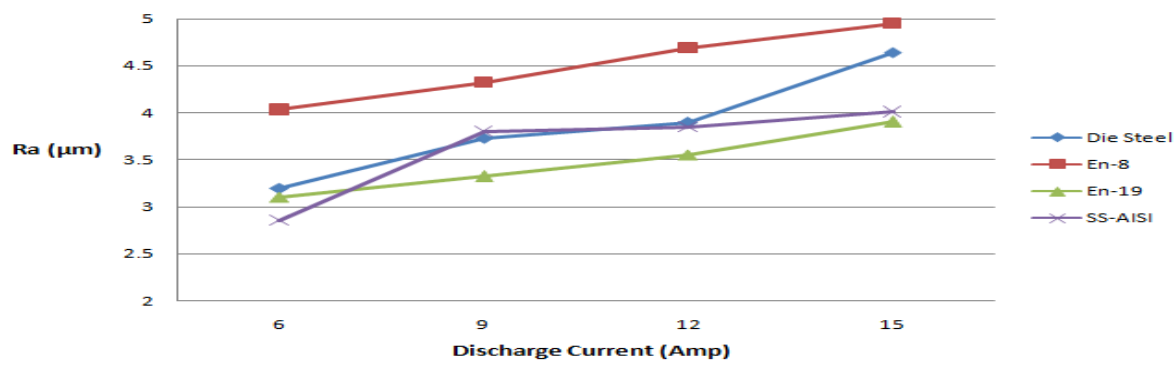

Fig. 1.9 Variation of Ra with Discharge current for various Hard steels using Cu electrode

From the figure 1.9 it can be concluded that for En- 8 the surface roughness value is highest and for En-19 it is lowest. The surface roughness for SS-AISI-440C increases rapidly upto 9A and then it increases very gradually for further increase in discharge current and for Die Steel D3 surface roughness increases gradually but remains in between to that of En-8 and En-19.

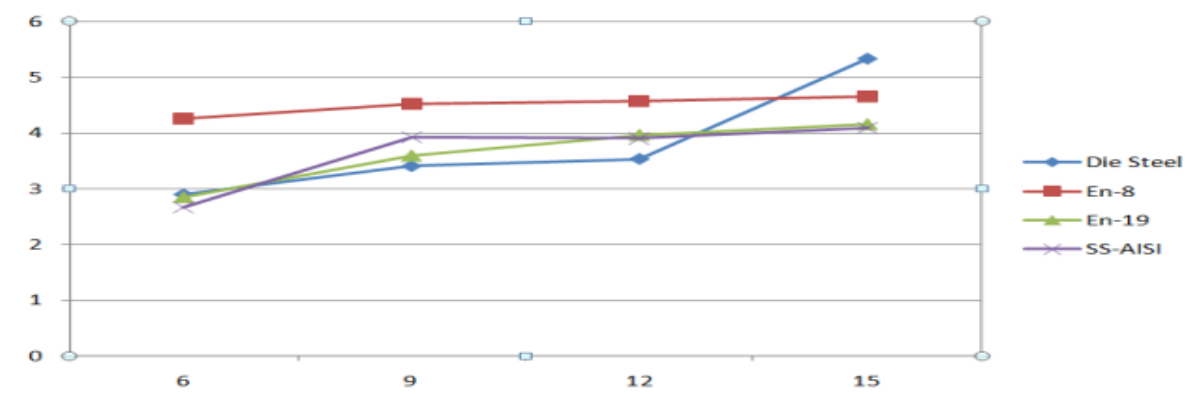

Fig. 2.0 Variation of Ra with Discharge current for various Hard steels using Al electrode

From the figure 2.0 it can be seen that for En-8 the surface roughness value is highest followed by SS-AISI440C and En-19 and for D3 it is lowest upto 9A. As the discharge current further increases the shape of the curves for En-8, En-19, SS-AISI-440C remains same but for die steel curve rises steeply.

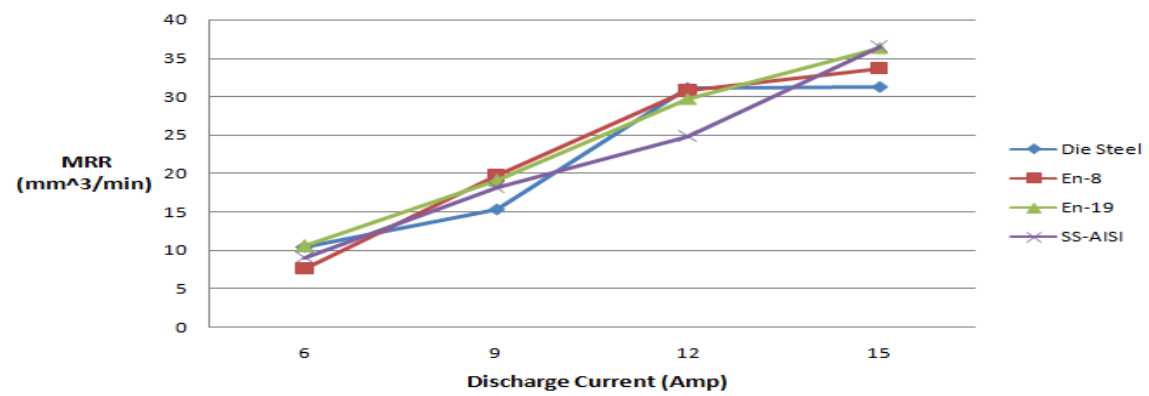

Fig 2.1 Variation of MRR with Discharge current for various Hard steels using $\mathrm{Cu}$ electrode 
From the figure 2.1 it can be observed that at initially at low current all workpieces shows almost same MRR. It is also seen that En-8 and En-19 gives similar reading of MRR upto 12A but for Die Steel-D3, MRR increases slowly upto 9A and increases steeply between 9A to 12A. The MRR for SS-AISI-440C shows a proportional increase upto 12A but it is less as compared to MRR of other three materials. At highest current, MRR for D3 is minimum, for En-8 it is moderate and it is maximum for En-19 and SS-AISI-440C.

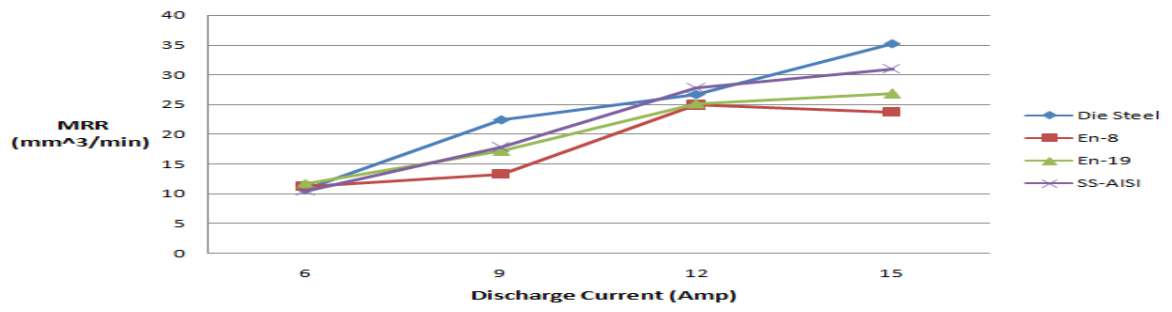

Fig 2.2 Variation of MRR with Discharge current for various Hard steels using Al electrode

From the figure 2.2 it can be seen that initially at low current value of $6 \mathrm{~A}$ all workpieces shows almost same MRR. At 9A highest MRR is shown by Die Steel D3 and lowest by En-8 while the other two materials show almost same MRR. At 12A MRR for all the materials is almost same whereas at 15A D3 shows the highest MRR followed by SS-AISI-440C, En-19 and En-8.

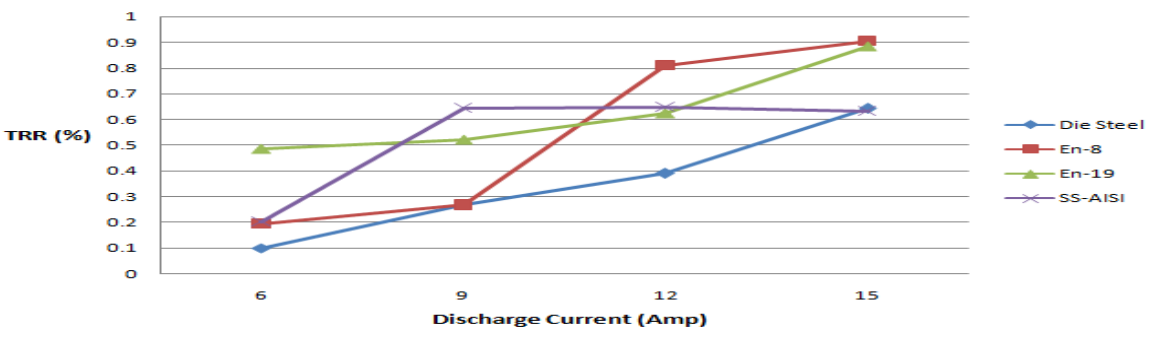

Fig 2.3 Variation of TRR with Discharge current for various Hard steels using Cu electrode

From the figure 2.3 it can be concluded that for D3, TRR is minimum relative to other work pieces. Initially En-8 shows a low value of TRR upto 9A but as the discharge current increases a steep increment occurs in TRR. For SS-AISI-440C, TRR increases rapidly upto 9A after which it shows almost constant TRR. For En-19 TRR increases gradually as the value of discharge current increases.

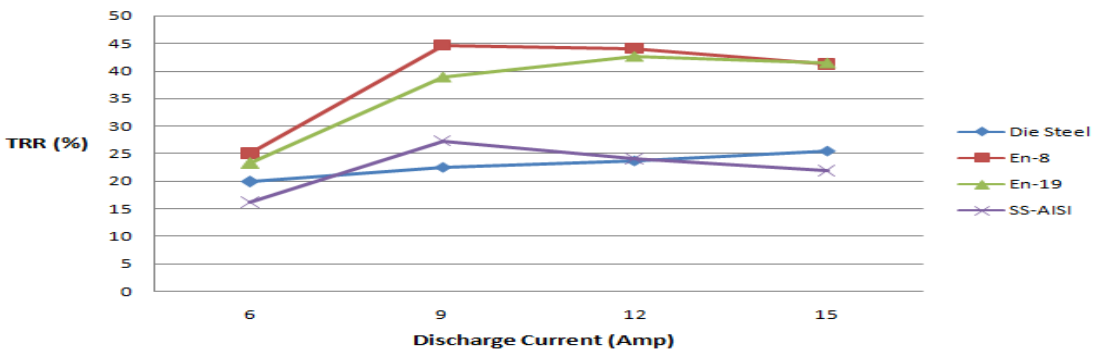

Fig 2.4 Variation of TRR with Discharge current for various Hard steels using Al electrode 
From the figure 2.4 it can be observed that SS-AISI-440C and Die Steel D3 shows a minimum value of TRR with respect to discharge current. The shape of the curve for D3 is almost constant while for SS-AISI-440C it first increases upto 9A and further decreases with the increase of discharge current. The highest TRR is shown by En-19 and at higher discharge current both En-8 and En-19 shows almost same values of TRR.

\section{Conclusion \& Future Work}

This Study has reveals the effects of discharge current on various machining parameters of Die-Sinking EDM including MRR, TRR and Surface Roughness in different hard materials. The graphs obtained shows the variation of considered process parameters with discharge current. The results can be utilised by researchers for carrying out further study on EDM. As an extension for future work a composite of Aluminium and Silicon carbide can be taken as workpiece for machining. In which fine silicon carbide powder is mixed into melting aluminium. En-31 and some other materials of En series which are difficult to be machined by conventional machining processes may also be considered. One can also employ a silver tungsten carbide electrode as a tool material for further research.

\section{Acknowledgment}

This research paper is made possible through the help and support from everyone including parents, teachers, family and friends. Especially I would like to dedicate my acknowledgement of gratitude towards the following significant advisors and contributors.

First and foremost, I would like to thank Mr. R Rajan for his esteemed guidance and support.

Secondly I would like to thank Ankit Chettri, Arvind Viswakarma, Dinesh Joshi and Arun Kumar for their kind help in carrying out this research.

Finally, I sincerely thank my family for their patience and support. The product of this research paper would not be possible without all of them.

\section{References}

[1] A.K.M. Asif Iqbal and Ahsan Ali Khan, "American Journal of Engineering and Applied Sciences", 3 (2): 396-402, 2010", ISSN 1941-7020, 2010.

[2] Trias Andromeda, Azli Yahya, Nor Hisham, Kamal Khalil, Ade Erawan, "Predicting Material Removal Rate of Electrical Discharge Machining (EDM) using Artificial Neural Network for High I-gap current", International Conference on Electrical, Control and Computer Engineering, Pahang, Malaysia, June 2122, 2011.

[3] M.M.Pawade and S.S.Banwait, "An Exhaustive Review of Die Sinking Electrical Discharge Machining Process and Scope for Future Research", World Academy of Science, Engineering and Technology, Vol:7 2013-06-26.

[4] Jesus Doval Gandoy, Ramon Pasandin, Bernardo Fernandez, "Electrical Discharge Machining for sharpening diamond disks", IAS 2004, 0-7803-8486-5/04, 2004 IEEE.

[5] Kuldeep Ojha, R.K. Garg, K.K. Singh, "MRR Improvement in Sinking Electrical Discharge Machining: A Review", Journal of Minerals \& Materials Characterization \& Engineering, Vol. 9, No. 8, pp. 709-739, 2010.

[6] H.K.Kansal, P.Singh, P.Kumar, "Technology and Research developments in Powder mixed electric discharge machining (PMEDM)", Journal of Materials Processing Technology, 184, 32-41, 2007.

[7] H.Ramasawmy and L.Blunt, "Effect of EDM process parameters on 3-d surface topography", Journal of 
Materials Processing Technology, 148, 155-164, 2004.

[8] S.Mahendran, R.Devarajan, T. Nagarajan, and A. Majdi, "A review of micro-EDM", Proceedings of the International Multiconference of Engineers and computer scientists (IMECS), Vol. 2, March 17-19, 2010, Hong Kong.

[9] G Krishna Mohana Rao, S.Satyanarayana, M Praveen, "Influence of Machining Parameters on Electric Discharge Machining of Maraging Steels-An Experimental Investigation", Proceedings of the World Congress on Engineering 2008 Vol. II, WCE 2008, July 2 - 4, 2008, London, U.K.

[10] G.Kibria, B.R.Sarkar \& B.B.Pradhan and B. Bhattacharyya, "Comparative study of different dielectrics for micro-EDM performance during micro hole machining of Ti-6Al-4V alloy," International Journal of Advanced Manufacturing Technology, 48: pp. 557-570, 2010.

[11] W.Koenig, D.F.Dauw, G. Levy and U.Panten, "EDM-future steps towards the machining of ceramics", Ann. CIRP: 37 (2), pp. 625-631, 1998.

[12] Samad Dadvandipour, "On the Experimental Study of Electric Discharge Machining (EDM) of P20 Type Tool Steel", SAMI 2013, IEEE 11th International Symposium on Applied Machine Intelligence and Informatics, January 31 - February 2, 2013, Slovakia.

[13] Yoshio Mizugaki, "Contouring Electrical Discharge Machining With On-Machine Measuring and Dressing of a Cylindrical Graphite Electrode", 0-7803-2775-6196, 1996, IEEE.

[14] Y.FTzeng. and N.H.Chiu, "Two-Phase Parameter Design for the Optimisation of the Electrical Discharge Machining Process Using a Taguchi Dynamic Experiment." International Journal of Advanced Manufacturing Technology, Vol.21, No 12, 2003, pp. 1005-1014.

[15] P.M George, B.K. Raghunath , L.M. Manocha and Ashish M. Warrier, "EDM machining of carboncarbon composite- A Taguchi approach", Journal of Materials Processing Technology, Vol. 145, Issue 1, 2004, pp 66-71.

[16] S.R.Nithin Aravind, S.Sowmyi and K.P.Yuvara, "Optimization of Metal removal rate and surface roughness on wire EDM using Taguchi method", IEEE-International Conference On Advances In Engineering, Science And Management (ICAESM -2012) March 30, 31, 2012.

[17] Krishna Kumar Dadsena, S. Sivasankar, and C. R. Jeyapaul, "A Study on Electrical Discharge Machining of ZrB2-SiC Composite using Grey Entropy Analysis", 978-1-4673-5630-5/13/2013 IEEE.

[18] Chen Jian, Sun Zhong-ming and LU Guo-dong, "Simulation for Electrode Wear Predication in DieSinking EDM Based on Geometry Model", 2013 Fifth Conference on Measuring Technology and Mechatronics Automation.

[19] K.H. Ho, S.T. Newman, "State of the art electrical discharge machining (EDM)", International Journal of Machine Tools \& Manufacture, 43, 1287-1300, 2003

[20] Ahmet Hascalik, Ulas Caydas, "Electrical Discharge Machining of Titanium Alloy (Ti-6AI-4V)", Applied Surface Sciences, 253, 9007-9016, 2007.

[21] E.I. Shobert, "What happens in EDM", E.C. Jameson (Ed.), Electrical discharge machining: Tooling methods and applications, Society of manufacturing engineers, pp. 3-4, 1983, Dearbern, Michigan.

[22] G. Boothroyd, A.K. Winston, "Non-conventional Machining Processes", Fundamentals of machining and machine tools, Marcel Dekker Inc., pp. 491, 1989, New York.

[23] M.P. Jahan, M. Rahman, Y.S. Wong, "A Review on the conventional and micro-electro discharge machining of tungsten carbide" International Journal of Machine Tools \& Manufacture, 51, 837-858, 2011.

[24] Nikhil Kumar, Lalit Kumar, Harichand Tewatia, Rakesh Yadav, " Comparative study for MRR on DieSinking EDM using electrode of copper and graphite", International Journal of Advanced Technology \& Engineering Research (IJATER), Vol. 2, Issue 2, ISSN: 2250-3536 May 2012.

[25] V.N. Gaitonde, S.R. Karnik, M. Faustino, J. Paulo Davim, "Machinability analysis in turning tugsten copper composite for application in EDM electrodes", International Journal of Refractory metals and hard materials, 28, 221-227, 2010.

[26] Han-Min Chow, Lieh-Dai Yang, Chin-Tien Lin, Yaun Feng Chen, "The use of SiC Powder in water as 
dielectric for Micro-slit EDM machining", Journal of Material Processing Technology, 195, pp. 160-170, 2008.

[27] K.S. Banker, S.P. Parmar, B.C. Parekh, "Review to performance improvement of Die-sinking EDM using powder mixed Dielectric fluid", International Journal of research in Modern Engineering and Emerging Technology", Vol. 1, Issue 3, ISSN:2320-6586, April 2013.

\section{Author Profile}

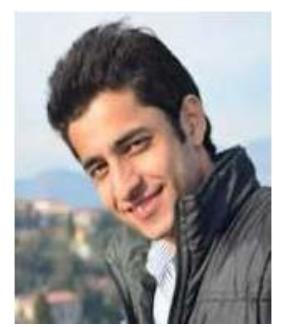

Mr Ashwani Kharola, is presently serving as Junior Research Fellow (JRF) in ITM. He is Mechanical Engineer and has completed B.Tech (Honours) in Mechanical Engineering M.Tech in CAD/CAM \& Robotics. He is pursuing $\mathrm{PhD}$ in Mechanical Engineering from Graphic Era (Deemed) University, Dehradun. He has done publications in Indian (01 Nos.)/ International (11 Nos.) double blind peer reviewed, ISSN Journals and IEEEICCIC International conference. He can be contacted at ashwanidaa@gmail.com.

Government of India, Ministry of Defence, Institute of Technology Management (ITM), Defence R\&D Organization (DRDO).

How to cite this paper: Ashwani Kharola,"Analysis of Various Machining Parameters of Electrical Discharge Machining (EDM) on Hard Steels using Copper and Aluminium Electrodes", IJEM, vol.5, no.1, pp.1-14, 2015.DOI: 10.5815/ijem.2015.01.01 